\title{
Gene expression signature based screening identifies ribonucleotide reductase as a candidate therapeutic target in Ewing sarcoma
}

\author{
Kelli L. Goss ${ }^{1}$ and David J. Gordon ${ }^{1}$ \\ ${ }^{1}$ Department of Pediatrics, Division of Pediatric Hematology/Oncology, University of Iowa, Iowa City, Iowa, USA \\ Correspondence to: David J. Gordon, email: david-j-gordon@viowa.edu \\ Keywords: Ewing sarcoma, ribonucleotide reductase, ciclopirox, iron chelator \\ Received: June 28, 2016 \\ Accepted: August 13, 2016 \\ Published: August 19, 2016
}

\section{ABSTRACT}

There is a critical need in cancer therapeutics to identify targeted therapies that will improve outcomes and decrease toxicities compared to conventional, cytotoxic chemotherapy. Ewing sarcoma is a highly aggressive bone and soft tissue cancer that is caused by the EWS-FLI1 fusion protein. Although EWS-FLI1 is specific for cancer cells, and required for tumorigenesis, directly targeting this transcription factor has proven challenging. Consequently, targeting unique dependencies or key downstream mediators of EWS-FLI1 represent important alternative strategies. We used gene expression data derived from a genetically defined model of Ewing sarcoma to interrogate the Connectivity Map and identify a class of drugs, iron chelators, that downregulate a significant number of EWS-FLI1 target genes. We then identified ribonucleotide reductase M2 (RRM2), the iron-dependent subunit of ribonucleotide reductase (RNR), as one mediator of iron chelator toxicity in Ewing sarcoma cells. Inhibition of RNR in Ewing sarcoma cells caused apoptosis in vitro and attenuated tumor growth in an in vivo, xenograft model. Additionally, we discovered that the sensitivity of Ewing sarcoma cells to inhibition or suppression of RNR is mediated, in part, by high levels of SLFN11, a protein that sensitizes cells to DNA damage. This work demonstrates a unique dependency of Ewing sarcoma cells on RNR and supports further investigation of RNR inhibitors, which are currently used in clinical practice, as a novel approach for treating Ewing sarcoma.

\section{INTRODUCTION}

Ewing sarcoma is an aggressive solid tumor that is treated with highly intensive, cytotoxic chemotherapy in combination with surgery and/or radiation [1]. Ewing sarcoma tumors are defined by a recurrent chromosomal translocation between the EWSR1 gene and various ETS genes; the most common fusion, EWS-FLI1, is present in $85 \%$ of cases [2]. The EWS-FLI1 oncoprotein functions, in part, as an aberrant transcription factor and drives the expression of a set of genes that is oncogenic in a permissive cell context [3]. EWS-FLI1 is an attractive therapeutic target in Ewing sarcoma tumors because it is both required for tumorigenesis and specific for tumor cells [4-8]. However, directly targeting a transcription factor is difficult and EWS-FLI1 has proven to be a challenging target. Consequently, an alternative therapeutic strategy in treating Ewing sarcoma is to identify downstream targets, or unique dependencies, of EWS-FLI1 [6, 9-18].

The identification of novel targets in Ewing sarcoma is complicated by the observation that the effects of EWSFLI1, including its impact on gene expression, are highly dependent on the cellular background [19]. Consequently, a number of different model systems, utilizing both gainof-function and loss-of-function approaches, have been developed in a wide variety of cell types to identify the downstream targets of EWS-FLI1. Although some target genes are conserved across multiple models, there are also significant differences between the gene sets identified using these different experimental approaches and cellular backgrounds. Hancock et al. used a metaanalysis approach with 13 independent data sets to address this heterogeneity and identify a 'core EWS-FLI1 gene expression signature [19].' Similarly, Kauer et al. used 
multiple experimental approaches to identify a consensus list of genes regulated by EWS-FLI1 [20]. Despite these efforts, the overlap between these lists is modest and the transcriptional impact of EWS-FLI1 remains an active area of investigation.

In this study, we used gene expression data from an inducible, genetically defined model of Ewing sarcoma, which we recently developed using human embryonic stem cells, to identify a set of EWS-FLI1 target genes [21]. We then used this gene set to query the Connectivity Map (Broad Institute), a computational resource that identifies links between drugs and gene expression signatures, and identify a class of drugs, iron chelators, that downregulate genes that are upregulated by EWSFLI1 [22]. We then identified ribonucleotide reductase M2 (RRM2), the iron-dependent subunit of ribonucleotide reductase (RNR), as one mediator of iron chelator toxicity in Ewing sarcoma cells [23]. Treatment of Ewing sarcoma cells with ciclopirox, as well as other drugs and siRNA that target RNR, induces apoptosis. In additional work, we discovered that high levels of SLFN11, a protein that sensitizes cells to drugs that cause DNA damage, is partially responsible for the toxicity of the RNR inhibitors toward Ewing sarcoma.

\section{RESULTS}

\section{Connectivity Map analysis identifies iron chelators as drugs that downregulate genes that are upregulated by EWS-FLI1}

In previous work, we developed an isogenic, inducible and reversible system to model the initiation of Ewing sarcoma in human embryonic stem cells [21]. We used this model system to identify 446 genes that are upregulated (Fold $>3$ and FDR $<0.01$ ), directly or indirectly, by the expression of the EWS-FLI1 oncoprotein (Supplementary Table 1). We then used Enrichr (http:// amp.pharm.mssm.edu/Enrichr/) to interrogate the Connectivity Map (Broad Institute) and identify drugs that downregulate these EWS-FLI1 target genes [24]. We chose to focus on drugs that downregulate genes that are upregulated by EWS-FLI1 because many of these genes, including NR0B1, NKX2-2, CCND1, BCL11B, EZH2, are critical for tumorigenesis [11, 25-27]. Seventeen drugs demonstrated a gene expression signature with significant (adjusted $p$-value $<0.05$ ) overlap with the EWS-FLI1 signature (Supplementary Table 2). Notably, three of these drugs are well-described iron chelators. The top hit identified in the analysis was ciclopirox (adjusted $p$-value $=8.22 \mathrm{e}-17$ ), which is an iron chelator that is used for the treatment of topical fungal infections (Figure 1A). The second hit, 5109870 (ChemBridge), is also an iron chelator [28]. Finally, deferoxamine, an iron chelator that is used to treat iron overload, exhibited significant overlap with the EWS-FLI1 expression signature as well. In addition to iron chelators, CMAP analysis also identified etoposide, which is a critical component of current therapy for Ewing sarcoma, as a significant hit (adjusted $p$-value $=$ $3.25 \mathrm{e}-10$, combined score $=36.33$ ). Similarly, resveratrol, which has been identified in other studies as a drug with potential therapeutic efficacy in Ewing sarcoma, was also identified in the analysis (adjusted $p$-value $=6.17 \mathrm{e}-11$, combined score $=36.68$ ) [29]. Additional, independent Ewing sarcoma gene expression data sets, which exhibit partial overlap with our gene set, also identified iron chelators as hits, although with lower enrichment scores (Supplementary Figure 1A-1C) [19, 20].

The CMAP gene expression data were generated using prostate, breast, melanoma, and leukemia cell lines [22]. To validate that ciclopirox causes similar gene expression changes in Ewing sarcoma cell lines, we performed gene expression microarray analysis on two Ewing sarcoma cell lines, A673 and EW8, treated with ciclopirox. As a comparison to the Ewing sarcoma cell lines, we also performed gene expression analysis on an osteosarcoma cell line, U2OS, and a telomeraseimmortalized fibroblast cell line, BJ-tert. The cells were treated with ciclopirox, or vehicle, for 24 hours and then mRNA was collected for microarray gene expression analysis. Treatment of the Ewing sarcoma cells with ciclopirox resulted in the downregulation of $\sim 45$ genes in each of the cell lines (Fold $>2$ and FDR $<0.05$; Supplementary Table 3 ) (Figure 1B). There was significant (hypergeometric $p$-value $<4 \mathrm{e}-30$ ) overlap in the downregulated genes between the Ewing sarcoma cell lines (Figure 1C). As predicted, CMAP analysis with these downregulated genes identified ciclopirox and 5109870 as significant hits (Figure 1D and 1E). Similar results were obtained using genes downregulated by ciclopirox in the U2OS and BJ-fibroblast cell lines, suggesting that some of the gene expression changes caused by ciclopirox are conserved between cell types (Supplementary Figure 1D$1 F)$. Finally, the genes downregulated by ciclopirox in the Ewing sarcoma cell lines overlap significantly with genes upregulated by EWS-FLI1 (hypergeometric $p$-values < 8e-8 and 4e-12; Supplementary Figure 1G).

\section{Treatment of Ewing sarcoma cells with ciclopirox results in an accumulation of cells in S-phase}

The genes that are downregulated by ciclopirox in the Ewing sarcoma cells (Supplementary Table 4) are significantly (Bonferonni $p$-values $<1 \mathrm{e}-5$ to $1 \mathrm{e}-8$ ) enriched for cell cycle genes (Figure 1F) [30]. Similarly, gene set enrichment analysis (GSEA) of the DMSO- and ciclopirox-treated cell lines identified that multiple gene sets related to the cell cycle are negatively correlated with ciclopirox (FDR $q$-value $=0.0$; Figure 1G) [31]. Based on 
A.

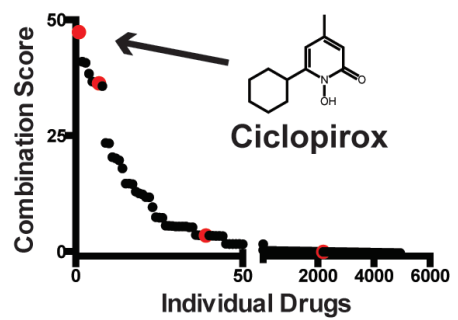

D.

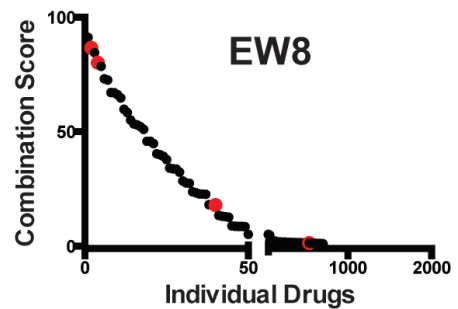

B.

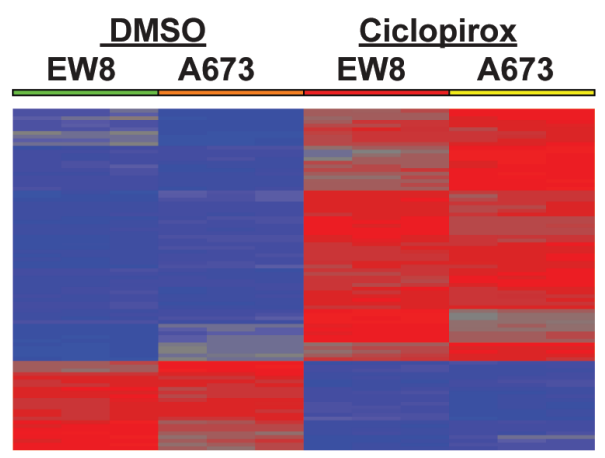

E.

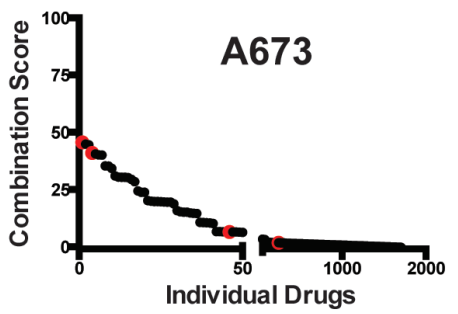

C.

A673 EW8

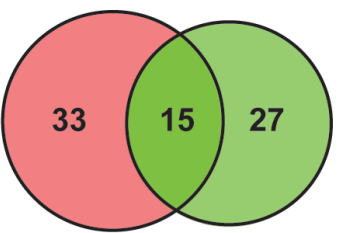

hypergeometric p-value $<4 \mathrm{e}-30$
F.

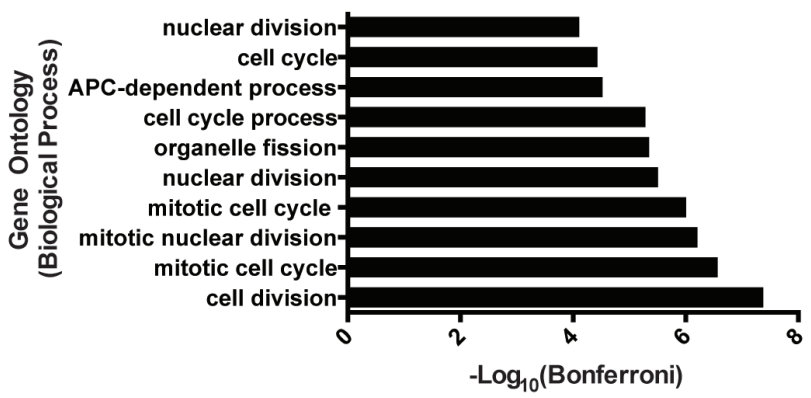

G.

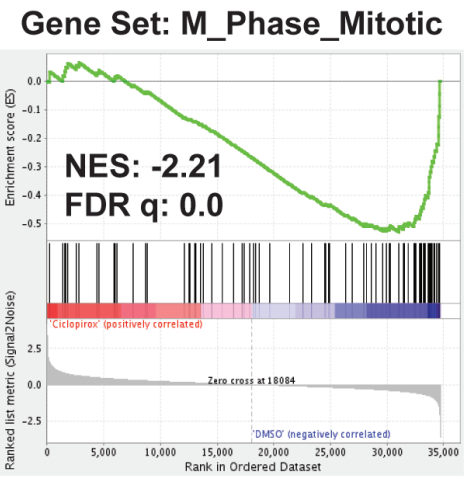

Figure 1: Identification of iron chelators as drugs that downregulate genes that are upregulated by EWS-FLI1. A. The Connectivity Map (CMAP) was used to identify drugs that downregulate genes that are upregulated by EWS-FLI1. The combined score, which is the product of the adjusted p-value and the z-score, is shown for the individual small molecules in CMAP. The red dots represent different cell lines (MCF7, PC3, HL60 and SKMEL5) treated with ciclopirox. Enrichment was calculated using the Enrichr resource [24]. The chemical structure of ciclopirox is shown as in insert in the graph. B. Heat map shows alteration in mRNA expression in Ewing sarcoma cell lines, EW8 and A673, treated with ciclopirox $(10 \mu \mathrm{M})$ or DMSO for 24 hours. C. Venn diagram demonstrates the significant overlap between genes downregulated by ciclopirox in the two Ewing sarcoma cell lines. D., E. CMAP was used to identify drugs that downregulate genes downregulated by ciclopirox in EW8 D. and A673 E. cells. The red dots represent different cell lines treated with ciclopirox. F. Gene ontology analysis of the genes downregulated by ciclopirox in the Ewing sarcoma cell lines was performed using ToppGene. G. Gene set enrichment analysis of expression data for Ewing sarcoma cells treated with ciclopirox shows a negative correlation between the M_Phase_Mitotic gene set and ciclopirox. The normalized enrichment scores (NER) and FDR q-values are shown. 
this gene enrichment data, we used propidium iodide to test whether ciclopirox affects the cell cycle progression of Ewing sarcoma cells. Treatment of Ewing sarcoma cells with ciclopirox for 24 hours led to an accumulation of cells in S-phase (Figures 2A and Supplementary Figure 2). To determine if the S-phase cells were replicating DNA we performed dual labeling with propidium iodide and EdU. The dual labeling demonstrated that treatment of Ewing sarcoma cells with ciclopirox results in a mixture of replicating and non-replicating S-phase cells (Figure 2B). Additionally, the replicating S-phase cells exhibited reduced incorporation of EdU compared to the control cells.

Iron chelator drugs are known to inhibit DNA replication and block cell cycle progression in late G1 or $\mathrm{S}$ phase by inhibiting ribonucleotide reductase $\mathrm{M} 2$ (RRM2), the iron-dependent subunit of ribonucleotide reductase (RNR) [23, 32]. RNR catalyzes the formation of deoxyribonucleotides from ribonucleotides and inhibiting RNR, by targeting either the RRM1 or RRM2 subunit of the enzyme, impairs DNA replication and causes replication stress [23]. RRM2 is highly expressed in Ewing sarcoma cells compared to other cancer types ( $p$-value $<$ 0.01; Supplementary Figure 3) and treatment of Ewing sarcoma cells with ciclopirox resulted in a significant reduction in deoxyribonucleotide levels, as predicted if RRM2 is a target of ciclopirox (Figure 2C). Similarly, treatment of Ewing sarcoma cells with ciclopirox caused an increase in single-strand DNA (ssDNA), which is an indicator of impaired DNA replication (Figure 2D) [33]. Treatment of Ewing sarcoma cells with ciclopirox also resulted in the phosphorylation of replication protein $\mathrm{A}$ (RPA32), which associates with ssDNA and is a marker of replication stress (Figure 2E) [33]. We also detected phosphorylation of checkpoint kinase 1 (Chk1), the major regulator of the response to impaired DNA replication, after treatment with ciclopirox (Figure 2F) [34].

\section{Treatment of Ewing sarcoma cells with ciclopirox results in impaired growth and apoptosis}

Treatment of Ewing sarcoma cell lines with ciclopirox for 72 hours caused a significant reduction in growth (Figure 3A), with IC50 values ranging from 500 $\mathrm{nM}$ to $3 \mu \mathrm{M}$. In contrast, ciclopirox was less effective at inhibiting the growth of other cell lines, including HT1080 (fibrosarcoma), U2OS (osteosarcoma), BJtert (telomerase-immortalized fibroblasts) and RPE-tert (telomerase-immortalized epithelial cells) (Figure 3B). Treatment with the highest concentration of ciclopirox $(50 \mu \mathrm{M})$ resulted in $<50 \%$ growth reduction in these cell lines. Ewing sarcoma cells were also sensitive to treatment with an additional iron chelator drug, deferasirox (Supplementary Figure 4A-4B). Notably, the addition of holo-transferrin, a source of biologically available iron, to the cell culture media significantly rescued the toxicity of ciclopirox toward Ewing sarcoma cells, demonstrating that iron is a target of ciclopirox (Figure 3C). However, the antioxidant $\mathrm{N}$-acetylcysteine, in contrast to holotransferrin, was unable to rescue the toxicity of ciclopirox, demonstrating that the effect of ciclopirox is not mediated by altering thiol-based redox homeostasis, as can be seen with other iron chelators (Figure 3D). Similarly, ciclopirox treatment did not have an effect on EWS-FLI1 levels (Supplementary Figure 5).

Next, we tested whether additional small molecule inhibitors of RNR could reduce the growth and viability of Ewing sarcoma cells. Hydroxyurea, a well-established inhibitor of RRM2, inhibited the growth of Ewing sarcoma cells at concentrations (IC50 range 165-300 $\mu \mathrm{M}$ ) that are significantly lower than concentrations typically used for cell cycle synchronization ( $>1 \mathrm{mM}$ ) (Figure 3E) [35]. Ewing sarcoma cells were also sensitive (IC50 range 2.4$10 \mathrm{nM}$ ) to gemcitabine, an inhibitor of RRM1 (Figure 3F). Furthermore, analysis of the Genomics of Drug Sensitivity in Cancer Project (http://www.cancerrxgene.org/) data, which includes 18 Ewing sarcoma cell lines and $>600$ other cancer cell lines, demonstrated that Ewing sarcoma cells are significantly more sensitive to gemcitabine than other cancer types ( $p$-value $=0.0013$ ) (Figure 3G) [36].

In addition to the effects on cell cycle, we also noted significant morphologic changes, suggestive of cell death, in the Ewing sarcoma cells treated with $10 \mu \mathrm{M}$ ciclopirox (Figure 4A), which is a drug concentration that significantly impairs the viability of all of the Ewing sarcoma cell lines (Figure 3B) and is an achievable serum concentration of the drug in vivo [32]. These morphologic changes coincided with cleavage of PARP-1, a marker of apoptosis (Figure 4B). Notably, an osteosarcoma cell line, U2OS, treated with ciclopirox did not demonstrate cleavage of PARP-1. Treatment of Ewing sarcoma cells with ciclopirox also resulted in an increase in the percentage of cells positive for annexin- $\mathrm{V}$ and propidium iodide (Figure 4C and 4D). Similarly, a luminescencebased assay (Caspase-Glo 3/7; Promega) demonstrated activation of caspase-3/7 in Ewing sarcoma cells treated with ciclopirox and hydroxyurea (Figure 4E). Gene set enrichment analysis of the DMSO- and ciclopirox-treated Ewing sarcoma cells also identified the upregulation of genes related to apoptosis in the cells treated with ciclopirox (Figure 4F).

\section{Treatment of Ewing sarcoma cells with siRNA targeting RNR results in impaired growth and apoptosis}

We then used siRNA to knockdown RRM2 in Ewing sarcoma cells to complement the small-molecule studies. Two different siRNAs, a "pool" set consisting of four unique siRNAs (si_RRM2_pool) and a well- 
A.
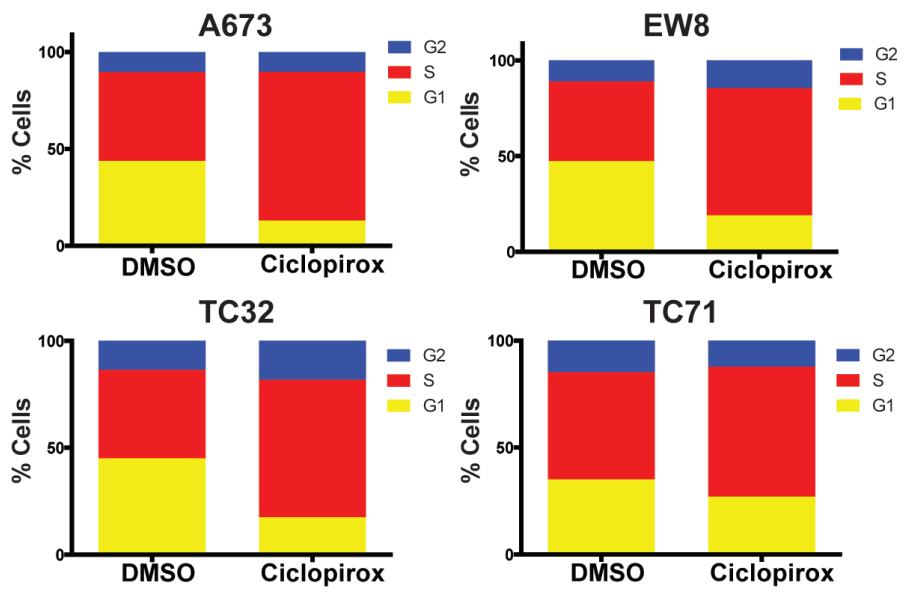

C.
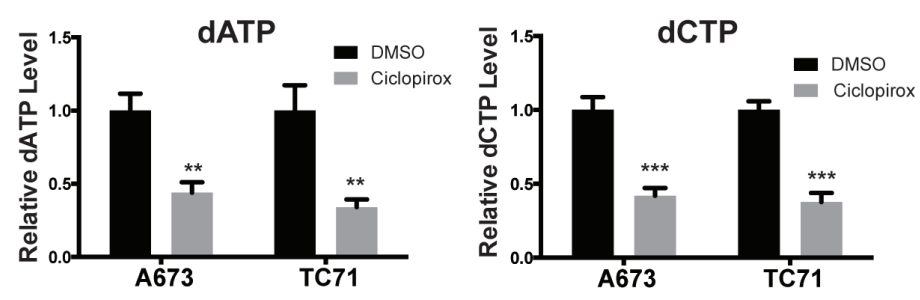

B.
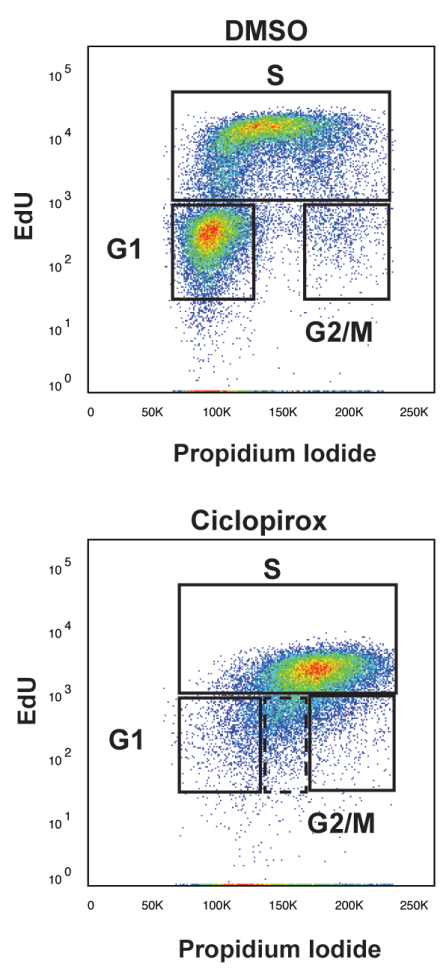

D.

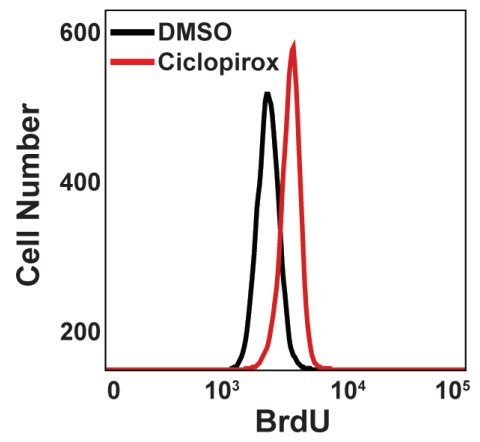

E.

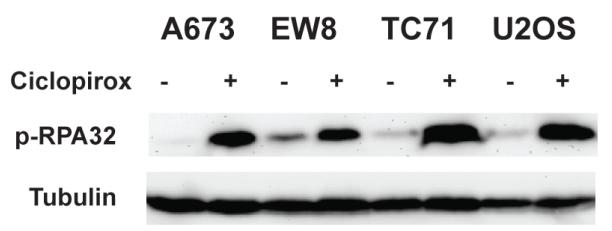

$\mathbf{F}$.

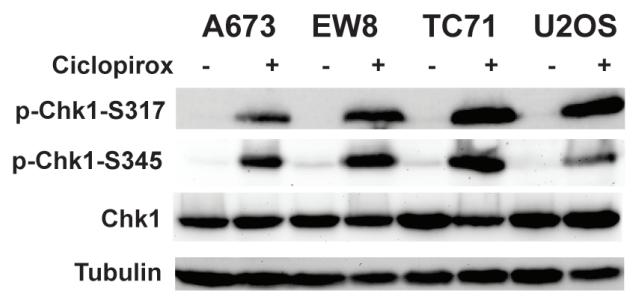

Figure 2: Ciclopirox impairs $\mathbf{S}$ phase progression of Ewing sarcoma cells. A. Four Ewing sarcoma cell lines were treated with ciclopirox $(10 \mu \mathrm{M})$ for 24 hours and then fixed to analyze their cell cycle distribution using propidium iodide. B. Cell cycle analysis with EdU and propidium iodide shows that treatment with ciclopirox $(10 \mu \mathrm{M})$ results in a mixture of replicating and non-replicating (dotted box) S phase cells. C. Treatment of Ewing sarcoma cell lines with ciclopirox $(10 \mu \mathrm{M})$ for 24 hours causes a reduction in dATP and dCTP levels. D. Quantification of ssDNA, using a non-denaturing BrdU assay, in cells treated with ciclopirox $(10 \mu \mathrm{M})$. E., F. Western blots showing that treatment of Ewing sarcoma cell lines with ciclopirox $(10 \mu \mathrm{M})$ causes phosphorylation of RPA32 E. and Chk1 F. 
A.

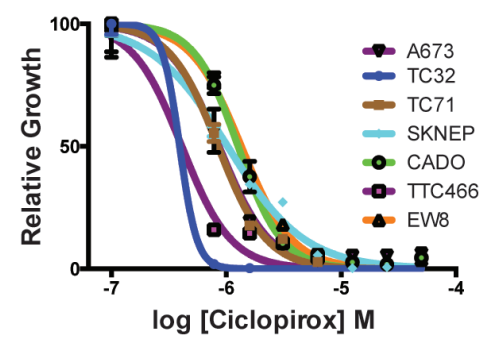

D.

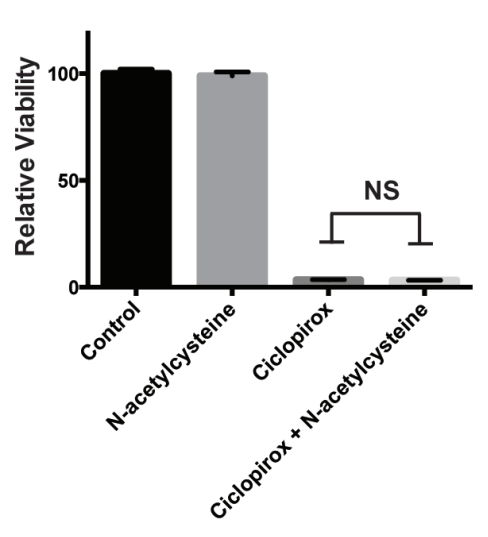

E.

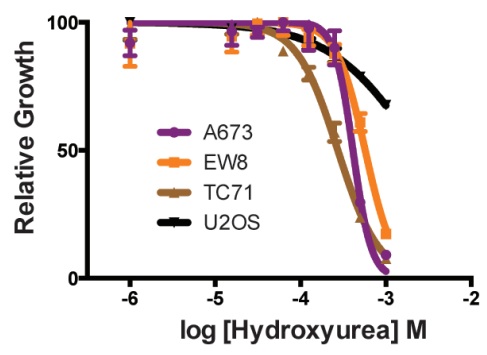

C.

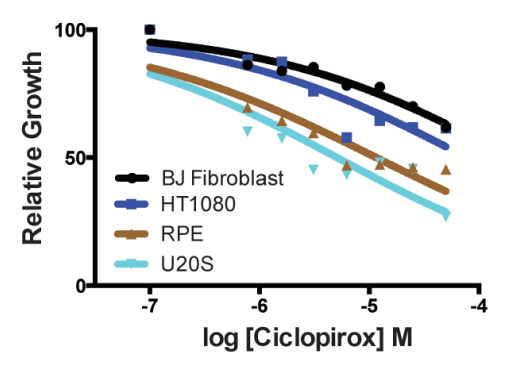

F.

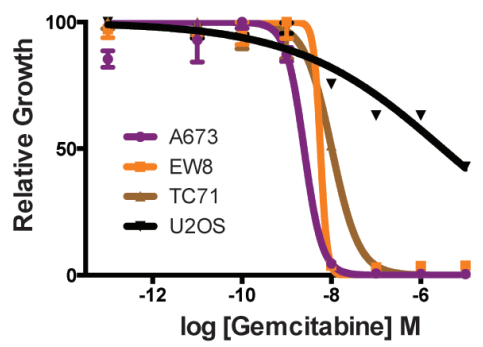

G.

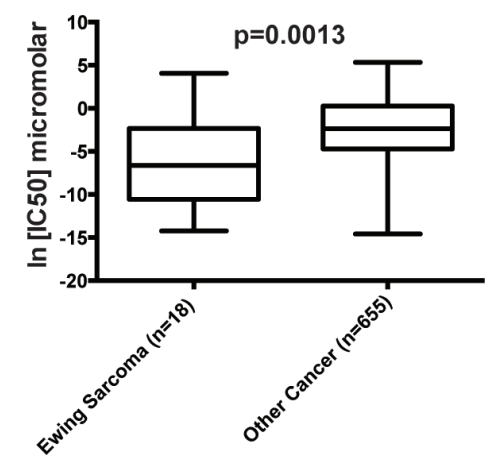

Figure 3: Inhibitors of ribonucleotide reductase impair the growth of Ewing sarcoma cells. A. Dose-response curves for seven Ewing sarcoma cell lines treated with different concentrations of ciclopirox for three days. Cell viability was assessed using the CellTiter-Glo Luminescent Assay. B. Dose-response curves for non-Ewing sarcoma cell lines treated with different concentrations of ciclopirox for three days. C. Relative viability of A673 cells treated with transferrin, ciclopirox and the combination of ciclopirox and transferrin. D. Relative viability of A673 cells treated with N-acetylcysteine, ciclopirox and the combination of ciclopirox and $\mathrm{N}$-acetylcysteine. E. Dose-response curves for Ewing sarcoma cell lines treated with different concentrations of hydroxyurea for three days. F. Dose-response curves for Ewing sarcoma cell lines treated with different concentrations of gemcitabine for three days. G. Analysis of Genomics of Drug Sensitivity in Cancer data shows that Ewing sarcoma cell lines are more sensitive to gemcitabine than other cancer cell lines. For the dose-response experiments, the results are representative of three independent experiments. Error bars represent mean \pm $\mathrm{SD}$ of three technical replicates. ${ }^{* *} P$-value $<0.01$. 
validated siRNA used in clinical trials (si_RRM2_R2B), were used to knockdown RRM2 (Figure 5A) [37, 38]. Knockdown of RRM2 with siRNA resulted in a significant reduction in cell growth (Figure 5B) and activation of caspase-3/7 (Figure 5C) in Ewing sarcoma cells, but not the other cell lines we tested (Figure 5D). Deconvolution of the si_RRM2_pool set showed that siRRM2_1 and siRRM2_3 were most effective at depleting RRM2 (Figure $5 \mathrm{E}$ ) and that knockdown efficiency correlated with growth inhibition (Figure 5F). To test the effects of RRM2 knockdown on gene expression, we performed gene expression analysis on A673 and EW8 cells treated with si_RRM2_R2B and a non-targeting siRNA (si_NT). There was significant overlap in the genes deregulated by ciclopirox and si_RRM2_R2B (hypergeometric $p$-values $<8 \mathrm{e}-25$ and $<7 \mathrm{e}-29$ ), as predicted if RRM2 is a target of ciclopirox (Figure 5G). More genes were deregulated by ciclopirox than the RRM2 siRNA, which likely reflects off-target effects of the drug. Finally, to exclude siRNA off-target effects, we generated an Ewing sarcoma cell line that expresses a RRM2 gene, under the control of a doxycycline-inducible promoter, that is resistant to siRNA knockdown (Figure 5H). Notably, expression of this siRNA-resistant RRM2 gene in Ewing sarcoma cells rescued the growth defect (Figure 5I) and caspase-3/7 activation (Figure 5J) caused by transfection of $\mathrm{si}$ RRM2_3 and knockdown of endogenous RRM2.

$\overline{\text { We }}$ also used a set of siRNAs targeting RRM1 (si RRM1_pool), the other subunit of RNR, to deplete RRM1 in Ewing sarcoma cells. These siRNAs were specific for RRM1 and did not affect levels of RRM2 (Supplementary Figure 6A). All four siRNAs in the pool showed effective knockdown of RRM1 (Supplementary Figure 6B) and significant inhibition of Ewing sarcoma cell growth (Supplementary Figure 6C).

\section{SLFN11 contributes to the sensitivity of Ewing sarcoma cells to inhibition of RNR}

The Ewing sarcoma cells were more sensitive to RNR inhibition and knockdown than the other cell lines we tested. Notably, Ewing sarcoma cell lines are also known to be sensitive to PARP-1 inhibitors and combinations of PARP-1 inhibitors with DNA-damaging agents. This sensitivity is mediated, in part, by high levels of SLFN11, which is a putative helicase and a direct transcriptional target of EWS-FLI1 that is highly expressed in Ewing sarcoma tumors [39, 40]. Since SLFN11 is known to sensitize cancer cells to a number of drugs that cause DNA-damage, including DNA synthesis inhibitors, we tested the hypothesis that the sensitivity of Ewing sarcoma cells to RNR inhibitors may be caused by elevated levels of SLFN11 [39, 41]. Figure 6A demonstrates that SLFN11 is highly expressed in Ewing sarcoma cell lines, as previously reported [39]. To test whether SLFN11 expression modulates the sensitivity of Ewing sarcoma cells to RRM2 knockdown we used siRNA to knockdown both SLFN11 and RRM2 in Ewing sarcoma cells (Figure $6 \mathrm{~B})$. Notably, the toxicity from knockdown of RRM2 was partially rescued by co-knockdown of SLFN11 (Figure 6C). Additionally, knockdown of SLFN11 also partially rescued Ewing sarcoma cells from the effects of ciclopirox on cell viability (Figure 6D).

\section{Ewing sarcoma xenografts respond to ciclopirox}

Based on the in vitro growth inhibition and apoptosis data, we next tested whether ciclopirox could inhibit the growth of tumor cells in suspension and in mouse xenograft experiments. Ciclopirox significantly inhibited the growth of Ewing sarcoma cells in an anchorageindependent growth assay (Figure 7A). For the xenograft experiment, NCr mice were subcutaneously injected with A673 cells and allowed to develop measurable tumors. The mice were then treated with oral ciclopirox $(25 \mathrm{mg} /$ $\mathrm{kg}$ ) or vehicle. Treatment with ciclopirox significantly decreased tumor size (Figure 7B). When the largest tumor in the control group reached $2000 \mathrm{~mm}^{3}$, all of the animals were euthanized and the tumors were excised and weighed. Ciclopirox significantly decreased tumor weight (Figure 7C). Ki-67 staining, a marker of cell proliferation, was also decreased in tumors from animals treated with ciclopirox (Figure 7D)

\section{DISCUSSION}

Despite aggressive therapy, the overall survival of patients with metastatic and non-metastatic Ewing sarcoma are $\sim 20 \%$ and $\sim 70 \%$, respectively [1]. Moreover, the current treatment of Ewing sarcoma, which consists of cytotoxic chemotherapy in combination with surgery and/or radiation, is associated with significant on- and offtreatment morbidities. EWS-FLI1 is an appealing target in Ewing sarcoma tumors and the identification of direct inhibitors of this transcription factor is an active area of investigation [5-7, 19, 42]. Other work has focused on identifying downstream targets, or unique vulnerabilities, of EWS-FLI1 [9-12, 15, 43, 44]. In this work, we used gene expression data from a genetically defined model of Ewing sarcoma to query the Connectivity Map and identify that Ewing sarcoma cells are sensitive to chemical inhibition and siRNA suppression of RNR. We used a doxycycline-inducible, siRNA-resistant, RRM2 transgene to demonstrate that the reduced viability and induction of apoptosis caused by siRNA knockdown of RRM2 is an on-target effect. We also identified that the elevated level of SLFN11 in Ewing sarcoma cells is responsible, in part, for the sensitivity of this sarcoma toward RNR inhibitors. Additionally, because multiple inhibitors of RNR are currently used in clinical oncology, we show that 
A.

Time (hr)

Ewing sarcoma
(A673)

Osteosarcoma

(U20S)
24

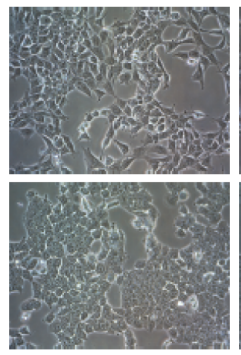

48

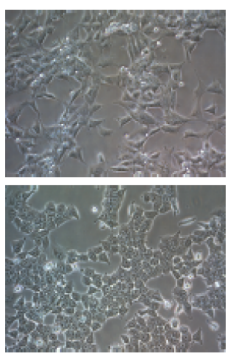

B.

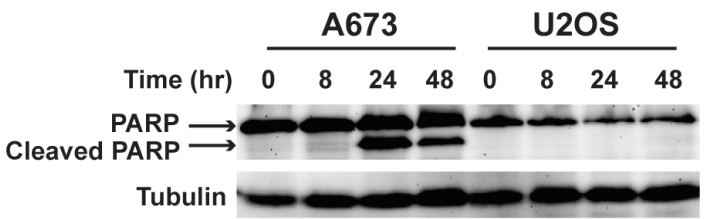

C.

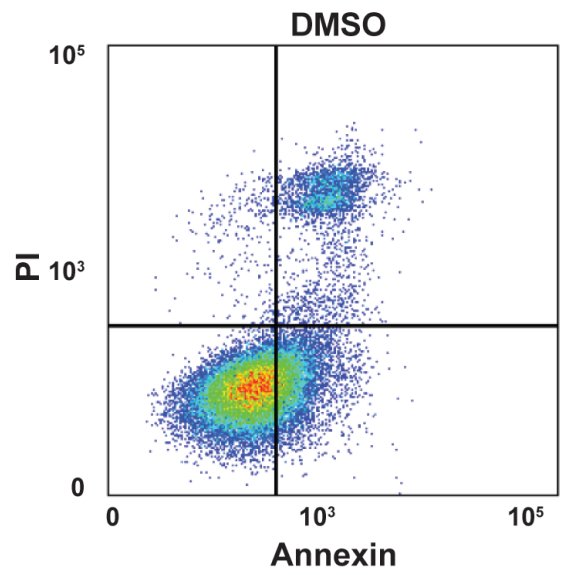

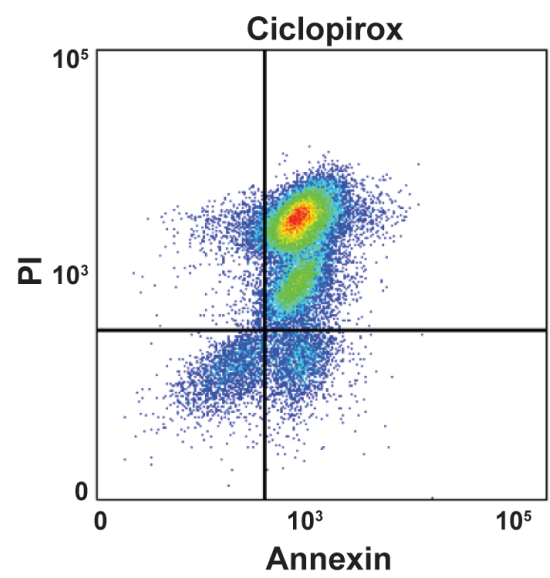

D.

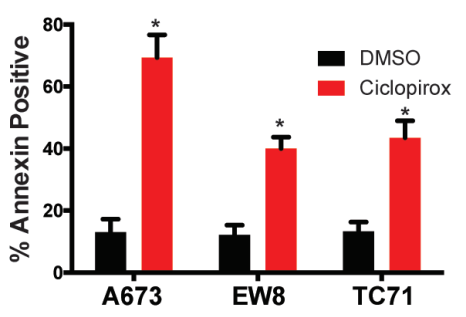

E.

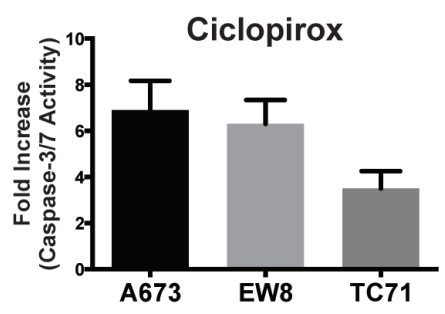

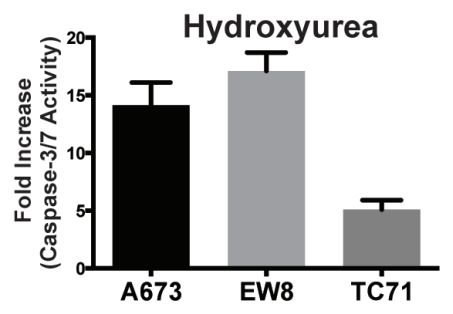

F.

Gene Set: Apoptosis

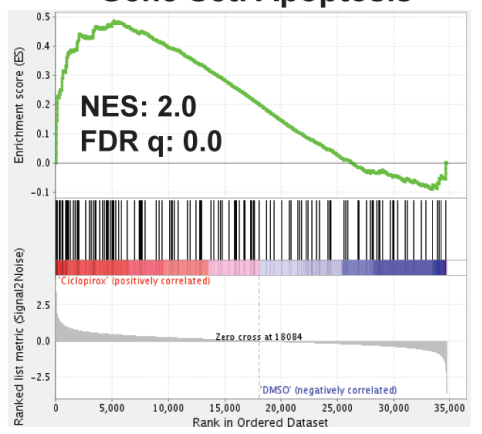

Figure 4: Ciclopirox induces apoptosis in Ewing sarcoma cells. A. Treatment with ciclopirox $(10 \mu \mathrm{M})$ causes morphologic changes in Ewing sarcoma cells. B. Western blot showing that treatment of Ewing sarcoma cells, but not U2OS osteosarcoma cells, with ciclopirox $(10 \mu \mathrm{M})$ causes cleavage of PARP-1. C. Flow cytometry plot for Annexin and PI staining of A673 cells treated with DMSO or ciclopirox $(10 \mu \mathrm{M})$ for two days. D. Percentage of Annexin-V positive cells for three Ewing sarcoma cell lines treated with ciclopirox (10 $\mu \mathrm{M})$ for two days. Results are representative of two independent experiments. Error bars represent mean $\pm \mathrm{SD}$ of two technical replicates. E. Fold increase in caspase-3/7 activation in three Ewing sarcoma cells lines treated with ciclopirox $(10 \mu \mathrm{M})$ and hydroxyurea $(500 \mu \mathrm{M})$ for three days. Fold change is relative to cells treated with DMSO. Figures are representative of three independent experiments. Data represent mean \pm SD of three technical replicates. F. Gene set enrichment analysis of expression data for Ewing sarcoma cells treated with ciclopirox shows a correlation between the Apoptosis gene set and ciclopirox. The normalized enrichment scores (NER) and FDR q-values are shown. $* P$-value $<0.05$. 
A.

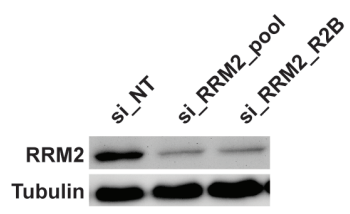

D.



G.

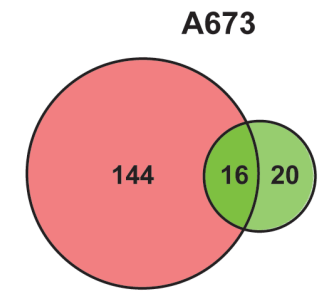

hypergeometric $p$-value $<8 \mathrm{e}-25$
B.

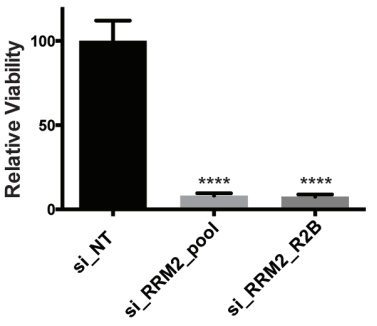

E.

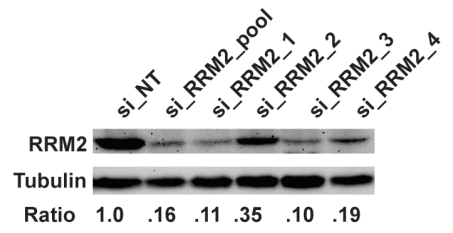

C.

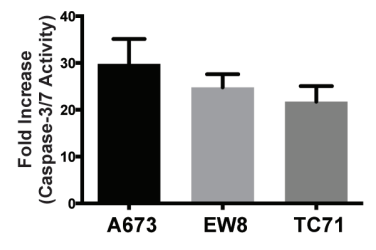

F.
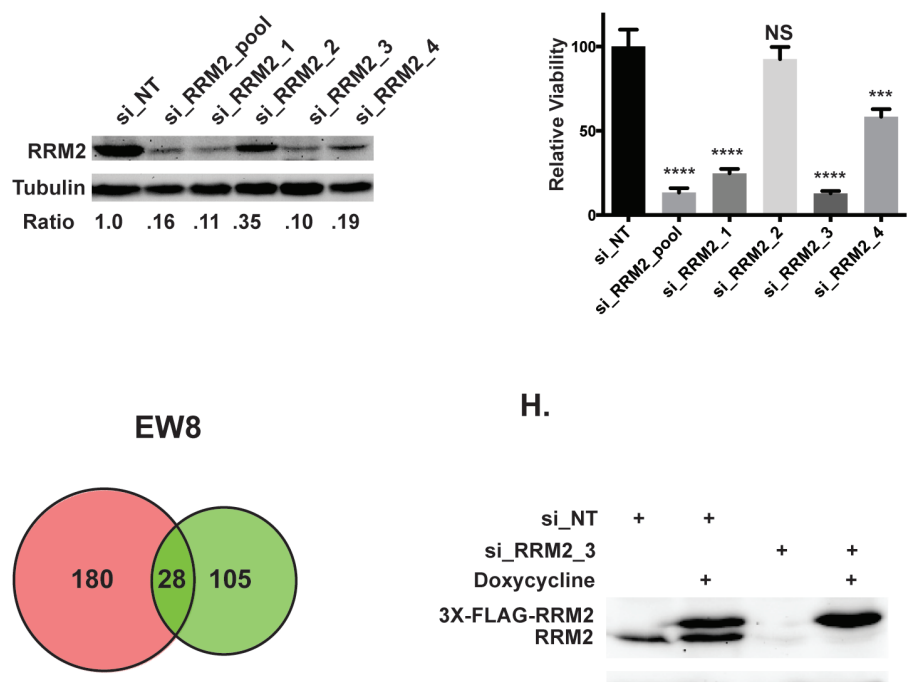

hypergeometric $\mathrm{p}$-value $<7 \mathrm{e}-29$
H.

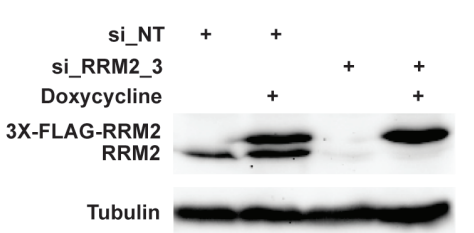

I.

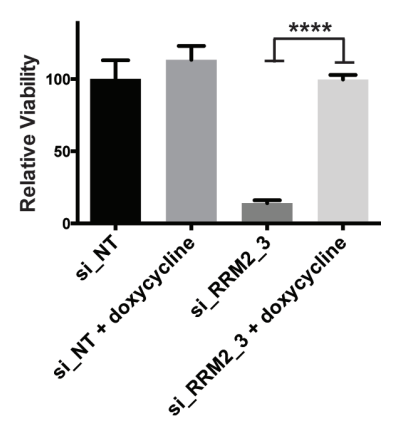

J.

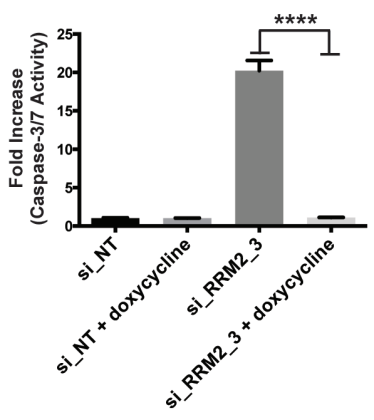

Figure 5: Knockdown of RRM2 using siRNA impairs the viability of Ewing sarcoma cells. A. Western blot showing levels of the RRM2 protein in A673 cells after transfection with two different siRNAs targeting RRM2 or a non-targeting siRNA (si_NT). B. Relative viability of A673 cells treated with a non-targeting siRNA or the two siRNAs that target RRM2. C., D. Increase in caspase-3/7 activation in Ewing sarcoma cells lines C. and non-Ewing sarcoma cell lines D. treated with siRRM2_R2B or si_NT for three days. Results are plotted as the fold increase in caspse-3/7 activity in the cells treated with siRRM2_R2B compared to the cells treated with si_NT. E. Western blot showing levels of the RRM2 protein after transfection with si_RRM2_pool or the individual siRNAs that compose the pool set. The relative expression level of RRM2 for each siRNA compared to the non-targeting siRNA is shown below the plot. F. Relative viability of A673 cells transfected with si_NT, si_RRM2_pool and the individual siRNAs that compose the pool (1-way ANOVA, Dunnett's post hoc test) G. Venn diagram demonstrates the overlap between genes deregulated by ciclopirox (pink) and si_RRM2_R2B (green). H. Western blot showing that the exogenous, doxycycline-inducible RRM2 gene, which is labeled with a $3 \mathrm{X}-\mathrm{FLAG}$ tag, is resistant to knockdown by si_RRM2_3. I. Relative viability of EW8 cells with doxycycline-inducible expression of siRNA-resistant RRM2 after transfection with si_RRM2_3. Cell viability was assessed using the CellTiter-Glo Luminescent Assay. J. Increase in caspase-3/7 activation in EW8 cells with doxycycline-inducible expression of siRNA-resistant RRM2 after transfection with si_RRM2_3. Fold change is relative to the si_NT cells. Data B., C., D., F., I., J. represent mean $\pm \mathrm{SD}, n=3$. ${ }^{* * *} p$-value $<0.001, * * * * p$-value $<0.0001$. 
ciclopirox inhibits the in vivo growth of Ewing sarcoma cells in a xenograft model.

Ciclopirox is a small-molecule inhibitor of RNR that targets the iron center of the RRM2 subunit through an iron-chelation mechanism [32]. Although ciclopirox was originally developed as a topical antifungal, oral ciclopirox was recently shown to display biological activity in a phase I trial in adult patients with advanced hematologic malignancies [45]. A potential limitation of oral ciclopirox, though, is that it is subject to first-pass metabolism and has a short half-life in vivo, consistent with the modest effect that we observed in the xenograft experiment [45]. However, from a clinical standpoint, other inhibitors of RNR with more favorable pharmacokinetics are used extensively in clinical oncology [46].

RRM1 can be targeted using both allosteric inhibitors (fludarabine and clofarabine) and catalytic inhibitors (cytarabine and gemcitabine) [47]. Similarly, iron chelators, (ciclopirox, triapine and deferoxamine)

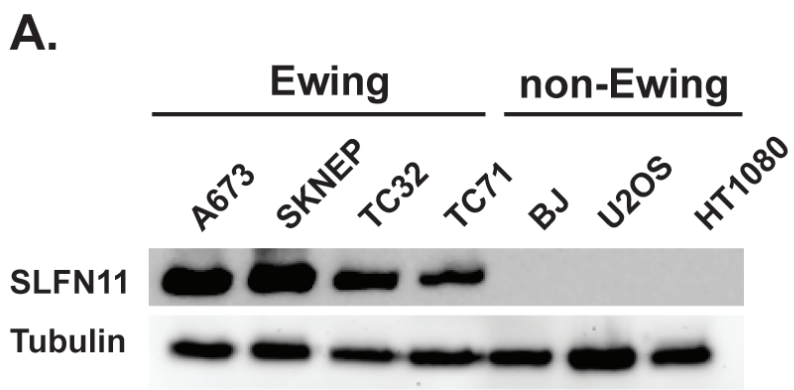

C.

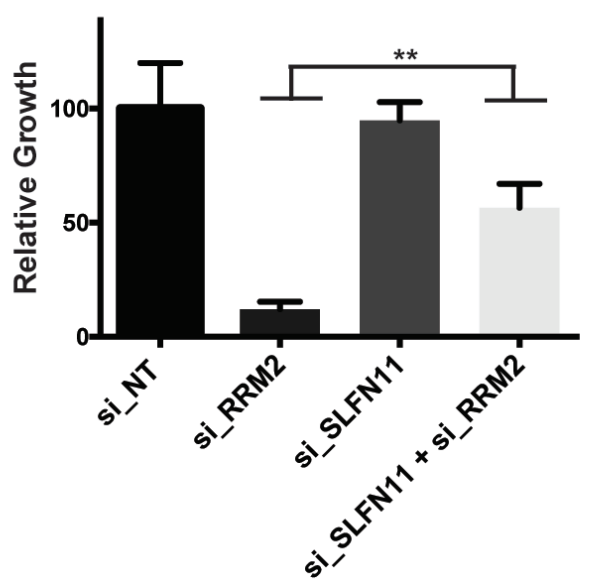

D.

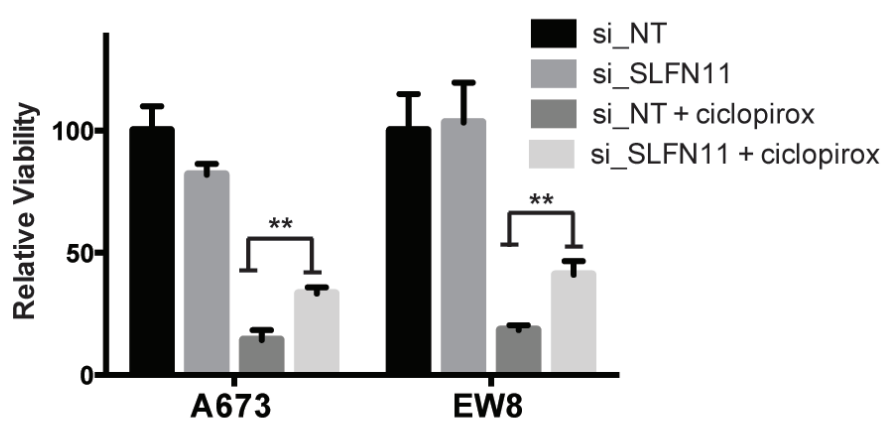

Figure 6: Elevated levels of SLFN11 contribute to the sensitivity of Ewing sarcoma cells to inhibition of RNR. A. Western blot showing levels of SLFN11 in Ewing sarcoma cells and non-Ewing sarcoma cell lines. B. Western blot showing levels of SLFN11 and RRM2 after transfection of cells with siRNAs that target SLFN11, RRM2 or both SLFN11 and RRM2. C. Concurrent knockdown of RRM2 and SLFN11 with siRNA partially rescues the effects of RRM2 knockdown on Ewing sarcoma cell viability. D. Knockdown of SLFN11 with siRNA in Ewing sarcoma cells partially rescues cells from the toxicity of ciclopirox. $* * P$-value $<0.01 ; * * * P$-value $<0.001$. 
sarcoma have shown variable efficacy, which may be related to differences in gemcitabine doses between the regimens [54, 55]. A clinical trial testing single-agent cytarabine in ten patients with relapsed or refractory Ewing sarcoma did not show efficacy [43]. However, in vitro work by Stegmaier et al. showed that cytarabine reduced EWS-FLI1 protein levels [56]. We did not observe a similar decrease in EWS-FLI1 levels in Ewing sarcoma cells treated with ciclopirox (Supplementary Figure 5), suggesting that the mechanism of cytarabineinduced toxicity may be different than iron chelators. Consequently, extrapolating the results from the clinical trial with cytarabine to other inhibitors of RNR may be challenging. Thus, we believe that further testing of RNR inhibitors, in particular drugs with improved pharmacokinetic properties and drugs in combination therapy, against Ewing sarcoma is supported by the wide availability of RNR inhibitors, the extensive clinical experience with this class of drugs, and the synergy between RNR inhibitors and other chemotherapy agents.
The overexpression of RRM2 can promote transformation and tumorigenesis via its cooperation with several oncogenes, but the overexpression of RRM1 has been shown to suppress malignant potential [57, 58]. Consequently, the roles of RRM1, RRM2 and RNR in tumorigenesis are complex [47]. However, inhibition or suppression of RNR in cancer cells is known to cause senescence [59-61]. For example, Aird et al. has shown that knockdown of RRM2 triggers aberrant DNA replication, activation of the DNA damage response and cellular senescence in primary cells and cancer cell lines, including melanoma and ovarian cancer [59-61]. In Ewing sarcoma cells, however, we show that inhibition of RNR leads to apoptosis. An aberrant response to DNA damage is well described in Ewing sarcoma tumors, although the mechanism is unclear [53].

The induction of apoptosis caused by RNR inhibitors in Ewing sarcoma cells is due, in part, to high levels of SLFN11. SLFN11 is a direct transcriptional target of EWS-FLI1 and overexpressed in Ewing sarcoma
A.

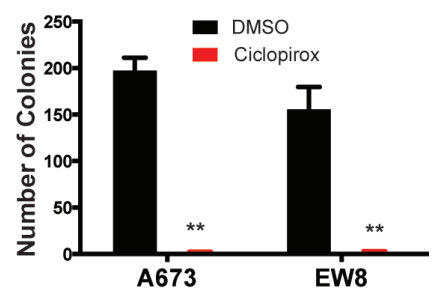

D.



B.

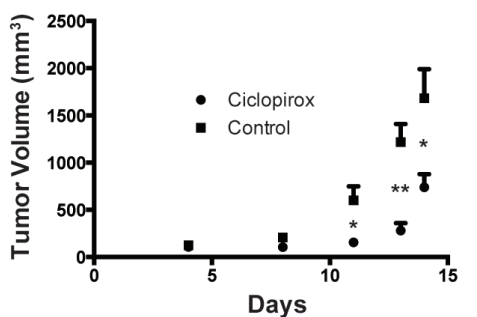

C.

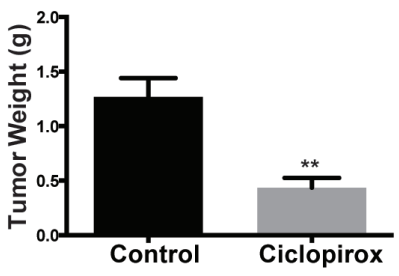

Figure 7: Ciclopirox inhibits the growth of Ewing sarcoma cells in suspension and in xenograft experiments. A. Growth of Ewing sarcoma colonies in methylcellulose-based media treated with ciclopirox $(10 \mu \mathrm{M})$ versus DMSO. Results are representative of two independent experiments. Error bars represent mean \pm SD of three technical replicates. B., C. A673 cells were engrafted in nude mice and treated by gavage with either vehicle or ciclopirox $(25 \mathrm{mg} / \mathrm{kg})(n=10$ mice per group). Tumor size during treatment B. and tumor weight at the end point $\mathbf{C}$. are shown. D. Immunohistochemical staining for proliferation marker Ki-67. The xenograft data are representative of two independent experiments. ${ }^{*} P$-value $<0.05, * * P$-value $<0.01$. 
tumors $[39,40]$. Recent work has shown that SLFN11 causes defects in checkpoint maintenance and homologous recombination repair [62]. Zoppoli et al. demonstrated that high levels of SLFN11 confer sensitivity of cancer cell lines to topoisomerase inhibitors, alkylating agents and DNA synthesis inhibitors, including gemcitabine [41]. Similarly, Tang et al. reported that SLFN11 is responsible for the high sensitivity of Ewing sarcoma cells to camptothecin and combinations of PARP inhibitors with temozolomide [39]. Notably, PARP inhibitors can cause replication stress by a "trapping" mechanism whereby the inhibitor stabilizes a PARP-DNA complex that interferes with DNA replication [63]. The SLFN11 data, in addition to providing a mechanistic explanation for the sensitivity of Ewing sarcoma cells to RNR inhibitors, also suggest that expression of this protein could function as a biomarker to predict drug response. It is important to note, however, that the rescue of drug toxicity by SLFN11 is only partial, which suggests that other pathways and proteins may play critical roles in modulating the response to RNR inhibitors. Notably, EWS-FLI1 has been implicated as a regulator of multiple aspects of the cellular response to genotoxic stress, although the mechanistic details remain to be elucidated [64]. In addition, haploinsufficiency of the EWSR1 gene in Ewing sarcoma tumors may also contribute to an impaired response to DNA damage [65].

We showed that suppression of RRM2 and loss of EWS-FLI1 expression result in the deregulation of an overlapping set of genes. One possible explanation for this overlap is that EWS-FLI1 regulates RNR levels. In particular, the RRM2 subunit of RNR is expressed at high levels in Ewing sarcoma cells relative to other cancers (Supplementary Figure 3). In our isogenic system, we detected a 5-fold and 140-fold downregulation of RRM1 and RRM2 mRNA levels, respectively, after loss of EWSFLI1 expression [21]. Kauer et al. also identified RRM2 as a gene regulated by EWS-FLI1 expression and Hancock et al. identified RRM1 in their meta-analysis [19, 20]. However, based on CHIP-seq experiments, EWS-FLI1 does not appear to directly regulate RRM1 or RRM2 expression levels, although effects on enhancers or other regulatory units cannot be excluded [66]. An alternative possibility is that EWS-FLI1 regulates RNR though an indirect mechanism. For example, EWS-FLI1 deregulates the activity of E2F transcription factors, which are critical regulators of the cell cycle and the primary regulators of RRM2 transcription [67]. However, because EWS-FLI1 targets multiple regulators of the cell cycle, including cyclin D1 and cyclin A1, it is difficult to conclude whether the changes in RRM2 expression after loss of EWS-FLI1 expression are a cause or consequence of the changes in the cell cycle [20,68]. Consequently, future work will need to investigate the regulation of RNR expression and activity in Ewing sarcoma.
In summary, we used gene expression data, in conjunction with the Connectivity Map, to identify that Ewing sarcoma tumors are sensitive to chemical inhibition and siRNA suppression of RNR. Overall, our work supports further study of RNR inhibitors in the treatment of Ewing sarcoma. In particular, the availability of clinically used inhibitors of RNR suggests the potential for translation of this work to the clinic.

\section{MATERIALS AND METHODS}

\section{Cell lines and culture}

Cell lines were maintained at $37^{\circ} \mathrm{C}$ in a $5 \% \mathrm{CO}_{2}$ atmosphere. The A673, TC32, TC71, SK-NEP, CADO, TTC466, and EW8 cell lines were kindly provided by Dr. Kimberly Stegmaier (Dana-Farber Cancer Institute, Boston, MA). The BJ-tert, HEK-293T, HT1080, RPE-tert, and U2OS cell lines were obtained from ATCC. Cells were grown in Dulbecco's Modified Eagle's Media (DMEM) supplemented with $10 \% \mathrm{FBS}, 100 \mathrm{IU} \mathrm{ml}^{-1}$ penicillin and $100 \mu \mathrm{g} \mathrm{ml}^{-1}$ streptomycin. Cell lines were authenticated by DNA fingerprinting using the short tandem repeat (STR) method.

\section{Chemical compounds}

Chemical compounds were purchased from Sigma (ciclopirox, gemcitabine, and hydroxyurea) and Selleck Chemical (deferasirox).

\section{Connectivity map analysis}

We used Enrichr (http://amp.pharm.mssm.edu/ Enrichr) to query the Connectivity Map (CMAP) [22, 24]. Enrichr, which extracts the top 100 and bottom 100 differentially expressed genes for each of the drugs in CMAP, uses three approaches to compute enrichment, including the Fisher exact test, a z-score ranking generated using random input gene lists and a combination of the Fisher exact test and z-score (combination score).

\section{Cell viability}

Cell proliferation was measured using CellTiter-Glo (Promega). Approximately $2-5 \times 10^{4}$ cells were plated per well of a 96-well plate. Cells were treated with a range of drug concentrations for three days. Luminescence readings were obtained after adding the CellTiter-Glo reagent using a FLUOstar Omega microplate reader (BMG Labtech). IC50 values were then calculated using log-transformed and normalized data (GraphPad Prism 5.0). 


\section{Gene expression}

For the microarray experiments, RNA was collected from three biological replicates of cells treated with DMSO, ciclopirox $(10 \mu \mathrm{M})$, si_NT, and si_RRM2_R2B using an RNeasy kit (Qiagen). The samples were then prepared for analysis and hybridized to HumanHT-12 v4 (Illumina) BeadChips by the Microarray Core at the University of Iowa. Partek Genomics Suite Version 6.6 was used to normalize the raw microarray data, preprocess the normalized data using default parameters and find differentially expressed probe sets. Gene set enrichment analysis (GSEA) was performed using the GSEA platform (www.broadinstitute.org/gsea) [31]. The gene expression files were deposited in the Gene Expression Omnibus (GEO) Repository under the accession number GSE79641. Venn diagrams were prepared using BioVenn (http://www. cmbi.ru.nl/cdd/biovenn/).

\section{Xenograft}

The Institutional Animal Care and Usage Committee at the University of Iowa approved the animal studies. Approximately $1.0 \times 10^{6} \mathrm{~A} 673$ cells were mixed with $30 \%$ matrigel and injected subcutaneously into the flanks of 6-week old, female $\mathrm{NCr}$ mice. After tumors were palpable, mice were divided into two cohorts and treated daily with ciclopirox $(25 \mathrm{mg} / \mathrm{kg})$ or vehicle control by oral gavage. Tumor volumes were measured periodically using calipers (volume $=0.5 \times$ length $\mathrm{x}$ width $^{2}$ ). All animals were sacrificed when the largest tumors in either the control or treatment groups reached $20 \mathrm{~mm}$ in any dimension. Tumors were then excised from all animals and weighed.

\section{Immunohistochemistry}

Tumor xenografts were fixed in formalin for immunohistochemical staining. Immunostaining for Ki67 was conducted using a rabbit anti-human Ki67 antibody (D2H10, Cell Signaling, \#9027, 1:400) on tumor sections. Staining was performed using the Vectastain $\mathrm{ABC}$ Kit (Vector Laboratories), according to the manufacturer's instructions.

\section{ssDNA quantification}

ssDNA was quantified using a flow cytometry protocol as described [69]. Exponentially growing cells were pulsed with $1 \mu \mathrm{M}$ BrdU (Sigma) for 36 hours and then fixed with methanol at $-20^{\circ} \mathrm{C}$. Cells were blocked in 3\% BSA in PBS for 30 minutes and then stained with a FITC-labeled, anti-BrdU monoclonal antibody (Sigma, Anti-BrdU, B44) for 1 hour. Flow cytometry was performed on a Becton Dickinson LSR II instrument.

\section{Gemcitabine sensitivity}

The sensitivity of Ewing sarcoma cell lines to gemcitabine, compared to other cancer cell lines, was assessed using data from the Genomics of Drug Sensitivity in Cancer resource (http://www.cancerrxgene.org/) [36].

\section{Apoptosis assays}

Caspase-3/7 activation was measured using the Caspase-Glo 3/7 Luminescence assay (Promega), according to the manufacturer's instructions. Annexin $\mathrm{V}$ was measured using a FITC Annexin V/Dead Cell Apoptosis Kit (ThermoFisher). The flow cytometry data were analyzed using FlowJo.

\section{siRNA transfection}

Cells $\left(1.5-3 \times 10^{5}\right)$ were plated one day prior to transfection in six-well plates. Cells were transfected with siRNA using Lipofectamine RNAiMax (ThermoFisher Scientific) according the manufacturer's instructions. siRRM1_pool, siRRM2_pool, and siSLFN11 were SMARTpool ON-TARGETplus reagents (GE Dharmacon). The sequences for si_RRM2_R2B and si NT were 5'-GAUUUAGCCAAGAAGUUCAGA-3' and 5'-UAGCGACUAAACACAUCAAUU-3', respectively.

\section{Cloning of siRNA-resistant RRM2}

The full length RRM2 cDNA, modified between base pairs 164-182 to 5'-CTACGGA ACCCAAAACGAA-3', was obtained as a gene block (IDT) and inserted into the Tet-One vector (pTO; Clontech). After verification by sequencing, the plasmid (pTO-RRM2) was used to make lentivirus.

\section{Lentivirus production and infection}

Lentivirus was produced by transfecting HEK-293T cells with the pTO-RRM2 plasmid and packaging plasmids (psPAX2 and pMD2.G) according to the FuGENE 6 (Roche) protocol. For the lentiviral transduction, Ewing sarcoma cells were incubated with $2 \mathrm{~mL}$ of virus and 6 $\mu \mathrm{g} / \mathrm{mL}$ of polybrene (Sigma-Aldrich) for 12-16 hours. Cells were selected in $1 \mu \mathrm{g} / \mathrm{mL}$ puromycin 48 hours after transduction.

\section{Statistical analysis}

Student's $t$-test was used to calculate p-values. Statistical analyses were conducted using GraphPad Prism 5.0. 


\section{ACKNOWLEDGMENTS}

We thank Stacia Koppenhafer and Brady Behling for helpful discussions.

\section{CONFLICTS OF INTEREST}

The authors indicate no potential conflicts of interest.

\section{FINANCIAL SUPPORT}

DJG is supported by a NCI K08 award (5K08 CA160346-03), a University of Iowa Dance Marathon Award, a Holden Comprehensive Cancer Center ACSIRG Seed Grant, and a University of Iowa Stead Family Research Award. The authors would also like to acknowledge use of the 1) University of Iowa Central Microscopy Research Facility, the 2) Iowa Institute of Human Genetics, and the 3) University of Iowa Flow Cytometry Facility.

\section{Author contributions}

Conception and design: D.J.G.

Development of methodology: D.J.G.

Acquisition of data: D.J.G. and K.L.G.

Analysis and interpretation of data: D.J.G. and K.L.G.

Review and/or revision of the manuscript: D.J.G. and K.L.G.

\section{Editorial note}

This paper has been accepted based in part on peerreview conducted by another journal and the authors' response and revisions as well as expedited peer-review in Oncotarget

\section{REFERENCES}

1. Balamuth NJ, Womer RB. Ewing's sarcoma. Lancet Oncology. 2010; 11(2):184-92.

2. Delattre O, Zucman J, Plougastel B, Desmaze C, Melot T, Peter M, Kovar H, Joubert I, de Jong P, Rouleau G. Gene fusion with an ETS DNA-binding domain caused by chromosome translocation in human tumours. Nature. 1992; 359(6391):162-5.

3. Lessnick SL, Dacwag CS, Golub TR. The Ewing's sarcoma oncoprotein EWS/FLI induces a p53-dependent growth arrest in primary human fibroblasts. Cancer Cell. 2002; 1(4):393-401.

4. Cote GM, Choy E. Update in treatment and targets in Ewing sarcoma. Hematol Oncol Clin North Am. 2013; 27(5):1007-
19.

5. Erkizan HV, Kong Y, Merchant M, Schlottmann S, Barber-Rotenberg JS, Yuan L, Abaan OD, Chou T-H, Dakshanamurthy S, Brown ML, Üren A, Toretsky JA. A small molecule blocking oncogenic protein EWS-FLI1 interaction with RNA helicase A inhibits growth of Ewing's sarcoma. Nature Medicine. 2009; 15(7):750-6.

6. Grohar PJ, Woldemichael GM, Griffin LB, Mendoza A, Chen QR, Yeung C, Currier DG, Davis S, Khanna C, Khan J, McMahon JB, Helman LJ. Identification of an Inhibitor of the EWS-FLI1 Oncogenic Transcription Factor by HighThroughput Screening. Journal of the National Cancer Institute. 2011; 103(12):962-78.

7. Chen C, Wonsey DR, Lemieux ME, Kung AL. Differential Disruption of EWS-FLI1 Binding by DNA-Binding Agents. PLoS ONE. 2013; 8(7):e69714-7.

8. Caropreso V, Darvishi E, Turbyville TJ, Ratnayake R, Grohar PJ, McMahon JB, Woldemichael G. Englerin A inhibits EWS-FLI1 DNA Binding in Ewings Sarcoma Cells. J Biol Chem. 2016; 291(19):10058-66.

9. Stegmaier K, Wong JS, Ross KN, Chow KT, Peck D, Wright RD, Lessnick SL, Kung AL, Golub TR. Signaturebased small molecule screening identifies cytosine arabinoside as an EWS/FLI modulator in Ewing sarcoma. PLoS Med. 2007; 4(4):e122.

10. Kovar H. Downstream EWS/FLI1 - upstream Ewing's sarcoma. Genome Med. 2010; 2(1):8

11. Kennedy AL, Vallurupalli M, Chen L, Crompton B, Cowley G, Vazquez F, Weir BA, Tsherniak A, Parasuraman S, Kim $\mathrm{S}$, Alexe G, Stegmaier K. Functional, chemical genomic, and super-enhancer screening identify sensitivity to cyclin D1/CDK4 pathway inhibition in Ewing sarcoma. Oncotarget. 2015; 6(30):30178-93. doi: 10.18632/ oncotarget.4903

12. Wilky BA, Kim C, McCarty G, Montgomery EA, Kammers K, DeVine LR, Cole RN, Raman V, Loeb DM. RNA helicase DDX3: a novel therapeutic target in Ewing sarcoma. Oncogene. 2016; 35(20):2574-83.

13. Mitsiades N, Poulaki V, Mitsiades C, Tsokos M. Ewing's sarcoma family tumors are sensitive to tumor necrosis factor-related apoptosis-inducing ligand and express death receptor 4 and death receptor 5. Cancer Res. 2001; 61(6):2704-12.

14. Hsu JH, Lawlor ER. BMI-1 suppresses contact inhibition and stabilizes YAP in Ewing sarcoma. Oncogene. 2011; 30(17):2077-85.

15. Rocchi A, Manara MC, Sciandra M, Zambelli D, Nardi F, Nicoletti G, Garofalo C, Meschini S, Astolfi A, Colombo MP, Lessnick SL, Picci P, Scotlandi K. CD99 inhibits neural differentiation of human Ewing sarcoma cells and thereby contributes to oncogenesis. J Clin Invest. 2010; 120(3):668-80.

16. Sankar S, Theisen ER, Bearss J, Mulvihill T, Hoffman LM, Sorna V, Beckerle MC, Sharma S, Lessnick SL. 
Reversible LSD1 inhibition interferes with global EWS/ ETS transcriptional activity and impedes Ewing sarcoma tumor growth. Clin Cancer Res. 2014; 20(17):4584-97.

17. Grohar PJ, Segars LE, Yeung C, Pommier Y, D'Incalci M, Mendoza A, Helman LJ. Dual Targeting of EWS-FLI1 Activity and the Associated DNA Damage Response with Trabectedin and SN38 Synergistically Inhibits Ewing Sarcoma Cell Growth. Clin Cancer Res. 2014; 20(5):1190203.

18. Tancredi R, Zambelli A, DaPrada GA, Fregoni V, Pavesi L, Riccardi A, Burdach S, Grohar PJ, D'Incalci M. Targeting the EWS-FLI1 transcription factor in Ewing sarcoma. Cancer Chemother Pharmacol. 2015; 75(6):1317-20.

19. Hancock JD, Lessnick SL. A transcriptional profiling metaanalysis reveals a core EWS-FLI gene expression signature. Cell Cycle. 2008; 7(2):250-6.

20. Kauer M, Ban J, Kofler R, Walker B, Davis S, Meltzer P, Kovar H. A molecular function map of Ewing's sarcoma. PLoS ONE. 2009; 4(4):e5415.

21. Gordon DJ, Motwani M, Pellman D. Modeling the initiation of Ewing sarcoma tumorigenesis in differentiating human embryonic stem cells. Oncogene. 2016; 35(24):3092-102.

22. Lamb J. The Connectivity Map: Using Gene-Expression Signatures to Connect Small Molecules, Genes, and Disease. Science. 2006; 313(5795):1929-35.

23. Nordlund P, Reichard P. Ribonucleotide reductases. Annu Rev Biochem. 2006; 75(1):681-706.

24. Chen EY, Tan CM, Kou Y, Duan Q, Wang Z, Meirelles GV, Clark NR, Ma'ayan A. Enrichr: interactive and collaborative HTML5 gene list enrichment analysis tool. BMC Bioinformatics. 2013; 14:128.

25. Kinsey M, Smith R, Lessnick SL. NR0B1 is required for the oncogenic phenotype mediated by EWS/FLI in Ewing's sarcoma. Mol Cancer Res. 2006; 4(11):851-9.

26. Kinsey M, Smith R, Iyer AK, McCabe ERB, Lessnick SL. EWS/FLI and its downstream target NR0B1 interact directly to modulate transcription and oncogenesis in Ewing's sarcoma. Cancer Res. 2009; 69(23):9047-55.

27. Smith R, Owen LA, Trem DJ, Wong JS, Whangbo JS, Golub TR, Lessnick SL. Expression profiling of EWS/ FLI identifies NKX2.2 as a critical target gene in Ewing's sarcoma. Cancer Cell. 2009; 9(5):405-16.

28. Coombs GS, Schmitt AA, Canning CA, Alok A, Low ICC, Banerjee N, Kaur S, Utomo V, Jones CM, Pervaiz S, Toone EJ, Virshup DM. Modulation of Wnt/b-catenin signaling and proliferation by a ferrous iron chelator with therapeutic efficacy in genetically engineered mouse models of cancer. Oncogene. 2011; 31(2):213-25.

29. Sonnemann J, Kahl M, Siranjeevi PM, Blumrich A, Blümel L, Becker S, Wittig S, Winkler R, Krämer OH, Beck JF. Reverse chemomodulatory effects of the SIRT1 activators resveratrol and SRT1720 in Ewing's sarcoma cells: resveratrol suppresses and SRT1720 enhances etoposide- and vincristine-induced anticancer activity. Journal of Cancer Research and Clinical Oncology. 2015; 142(1):1726.

30. Chen J, Bardes EE, Aronow BJ, Jegga AG. ToppGene Suite for gene list enrichment analysis and candidate gene prioritization. Nucleic Acids Research. 2009; 37(Web Server):W305-11.

31. Subramanian A, Tamayo P, Mootha VK, Mukherjee S, Ebert BL, Gillette MA, Paulovich A, Pomeroy SL, Golub TR, Lander ES, Mesirov JP. Gene set enrichment analysis: a knowledge-based approach for interpreting genomewide expression profiles. Proc Natl Acad Sci USA. 2005; 102(43):15545-50.

32. Eberhard Y, McDermott SP, Wang X, Gronda M, Venugopal A, Wood TE, Hurren R, Datti A, Batey RA, Wrana J, Antholine WE, Dick JE, Schimmer AD. Chelation of intracellular iron with the antifungal agent ciclopirox olamine induces cell death in leukemia and myeloma cells. Blood. 2009; 114(14):3064-73.

33. Zou L, Elledge SJ. Sensing DNA damage through ATRIP recognition of RPA-ssDNA complexes. Science. 2003; 300(5625):1542-8.

34. Bartek J, Lukas J. Chk1 and Chk2 kinases in checkpoint control and cancer. Cancer Cell. 2003; 3(5):421-9.

35. Petermann E, Orta ML, Issaeva N, Schultz N, Helleday T. Hydroxyurea-Stalled Replication Forks Become Progressively Inactivated and Require Two Different RAD51-Mediated Pathways for Restart and Repair. Mol Cell. 2010; 37(4):492-502.

36. Yang W, Soares J, Greninger P, Edelman EJ, Lightfoot H, Forbes S, Bindal N, Beare D, Smith JA, Thompson IR, Ramaswamy S, Futreal PA, Haber DA, et al. Genomics of Drug Sensitivity in Cancer (GDSC): a resource for therapeutic biomarker discovery in cancer cells. Nucleic Acids Research. 2012; 41(D1):D955-61.

37. Heidel JD, Liu JYC, Yen Y, Zhou B, Heale BSE, Rossi JJ, Bartlett DW, Davis ME. Potent siRNA Inhibitors of Ribonucleotide Reductase Subunit RRM2 Reduce Cell Proliferation In vitro and In vivo. Clinical Cancer Research. 2007; 13(7):2207-15.

38. Davis ME, Zuckerman JE, Choi CHJ, Seligson D, Tolcher A, Alabi CA, Yen Y, Heidel JD, Ribas A. Evidence of RNAi in humans from systemicallyadministered siRNA via targeted nanoparticles. Nature. 2011; 464(7291):1067-70.

39. Tang SW, Bilke S, Cao L, Murai J, Sousa FG, Yamade M, Rajapakse V, Varma S, Helman LJ, Khan J, Meltzer PS, Pommier Y. SLFN11 Is a Transcriptional Target of EWS-FLI1 and a Determinant of Drug Response in Ewing Sarcoma. Clin Cancer Res. 2015; 21(18):4184-93.

40. Barretina J, Caponigro G, Stransky N, Venkatesan K, Margolin AA, Kim S, Wilson CJ, Lehár J, Kryukov GV, Sonkin D, Reddy A, Liu M, Murray L, et al. The Cancer Cell Line Encyclopedia enables predictive modelling of anticancer drug sensitivity. Nature. 2012; 483(7391):603-7. 
41. Zoppoli G, Regairaz M, Leo E, Reinhold WC, Varma S, Ballestrero A, Doroshow JH, Pommier Y. Putative DNA/ RNA helicase Schlafen-11 (SLFN11) sensitizes cancer cells to DNA-damaging agents. Proc Natl Acad Sci USA. 2012; 109(37):15030-5

42. Lessnick SL, Ladanyi M. Molecular Pathogenesis of Ewing Sarcoma: New Therapeutic and Transcriptional Targets. Annu Rev Pathol Mech Dis. 2012; 7(1):145-59.

43. DuBois SG, Krailo MD, Lessnick SL, Smith R, Chen Z, Marina N, Grier HE, Stegmaier K. Phase II study of intermediate-dose cytarabine in patients with relapsed or refractory Ewing sarcoma: A report from the Children's Oncology Group. Pediatr Blood Cancer. 2009; 52(3):324-7.

44. Crompton BD, Carlton AL, Thorner AR, Christie AL, Du J, Calicchio ML, Rivera MN, Fleming MD, Kohl NE, Kung AL, Stegmaier K. High-throughput tyrosine kinase activity profiling identifies FAK as a candidate therapeutic target in Ewing sarcoma. Cancer Res. 2013; 73(9):2873-83.

45. Minden MD, Hogge DE, Weir SJ, Kasper J, Webster DA, Patton L, Jitkova Y, Hurren R, Gronda M, Goard CA, Rajewski LG, Haslam JL, Heppert KE, et al. Oral ciclopirox olamine displays biological activity in a phase I study in patients with advanced hematologic malignancies. Am J Hematol. 2014; 89(4):363-8.

46. Cerqueira NM, Pereira S, Fernandes PA, Ramos MJ. Overview of ribonucleotide reductase inhibitors: an appealing target in anti-tumour therapy. Curr Med Chem. 2005; 12(11):1283-94.

47. Aye Y, Li M, Long MJC, Weiss RS. Ribonucleotide reductase and cancer: biological mechanisms and targeted therapies. Oncogene. 2015; 34(16):2011-21.

48. Zhou B, Su L, Hu S, Hu W, Yip MLR, Wu J, Gaur S, Smith DL, Yuan YC, Synold TW, Horne D, Yen Y. A SmallMolecule Blocking Ribonucleotide Reductase Holoenzyme Formation Inhibits Cancer Cell Growth and Overcomes Drug Resistance. Cancer Res. 2013; 73(21):6484-93.

49. Jones RJ, Baladandayuthapani V, Neelapu S, Fayad LE, Romaguera JE, Wang M, Sharma R, Yang D, Orlowski RZ. HDM-2 inhibition suppresses expression of ribonucleotide reductase subunit M2, and synergistically enhances gemcitabine-induced cytotoxicity in mantle cell lymphoma. Blood. 2011; 118(15):4140-9.

50. Finch RA, Liu M, Grill SP, Rose WC, Loomis R, Vasquez KM, Cheng Y, Sartorelli AC. Triapine (3-aminopyridine2-carboxaldehyde- thiosemicarbazone): A potent inhibitor of ribonucleotide reductase activity with broad spectrum antitumor activity. Biochemical Pharmacology. 2000; 59(8):983-91.

51. Lin ZP, Ratner ES, Whicker ME, Lee Y, Sartorelli AC. Triapine Disrupts CtIP-Mediated Homologous Recombination Repair and Sensitizes Ovarian Cancer Cells to PARP and Topoisomerase Inhibitors. Molecular Cancer Research. 2014; 12(3):381-93.

52. Brenner JC, Feng FY, Han S, Patel S, Goyal SV, Bou-
Maroun LM, Liu M, Lonigro R, Prensner JR, Tomlins SA, Chinnaiyan AM. PARP-1 inhibition as a targeted strategy to treat Ewing's sarcoma. Cancer Res. 2012; 72(7):1608-13.

53. Stewart E, Goshorn R, Bradley C, Griffiths LM, Benavente C, Twarog NR, Miller GM, Caufield W, Freeman BB III, Bahrami A, Pappo A, Wu J, Loh A, et al. Targeting the DNA Repair Pathway in Ewing Sarcoma. Cell Reports. 2014; 9(3):829-41.

54. Mora J, Ofelia Cruz C, Parareda A, de Torres C. Treatment of Relapsed/Refractory Pediatric Sarcomas With Gemcitabine and Docetaxel. J Pediatr Hematol Oncol. 2009; 31(10):723-9.

55. Fox E, Patel S, Wathen JK, Schuetze S, Chawla S, Harmon D, Reinke D, Chugh R, Benjamin RS, Helman LJ. Phase II study of sequential gemcitabine followed by docetaxel for recurrent Ewing sarcoma, osteosarcoma, or unresectable or locally recurrent chondrosarcoma: results of Sarcoma Alliance for Research Through Collaboration Study 003. The Oncologist. 2012; 17(3):321-9.

56. Stegmaier K, Wong JS, Ross KN, Chow KT, Peck D, Wright RD, Lessnick SL, Kung AL, Golub TR. Signaturebased small molecule screening identifies cytosine arabinoside as an EWS/FLI modulator in Ewing sarcoma. PLoS Med. 2007; 4(4):702-14.

57. Fan H, Villegas C, Huang A, Wright JA. The mammalian ribonucleotide reductase R2 component cooperates with a variety of oncogenes in mechanisms of cellular transformation. Cancer Res. 1998; 58(8): 1650-3.

58. Fan H, Huang A, Villegas C, Wright JA. The R1 component of mammalian ribonucleotide reductase has malignancysuppressing activity as demonstrated by gene transfer experiments. Proc Natl Acad Sci USA.1997; 94(24):131816.

59. Aird KM, Worth AJ, Snyder NW, Lee JV, Sivanand S, Liu Q, Blair IA, Wellen KE, Zhang R. ATM Couples Replication Stress and Metabolic Reprogramming during Cellular Senescence. Cell Reports. 2015;11(6):893-901.

60. Aird KM, Li H, Xin F, Konstantinopoulos PA, Zhang R. Identification of ribonucleotide reductase $\mathrm{M} 2$ as a potential target for pro-senescence therapy in epithelial ovarian cancer. Cell Cycle. 2013; 13(2):199-207.

61. Aird KM, Zhang G, Li H, Tu Z, Bitler BG, Garipov A, Wu H, Wei Z, Wagner SN, Herlyn M, Zhang R. Suppression of Nucleotide Metabolism Underlies the Establishment and Maintenance of Oncogene-Induced Senescence. Cell Reports. 2013; 3(4):1252-65.

62. Mu Y, Lou J, Srivastava M, Zhao B, Feng XH, Liu T, Chen J, Huang J. SLFN11 inhibits checkpoint maintenance and homologous recombination repair. EMBO Rep. 2016; 17(1):94-109.

63. Murai J, Huang S-YN, Das BB, Renaud A, Zhang Y, Doroshow JH, Ji J, Takeda S, Pommier Y. Trapping of PARP1 and PARP2 by Clinical PARP Inhibitors. Cancer Res. 2012; 72(21):5588-99. 
64. Ghosal G, Yustein J. EWS-FLI1 Regulates Genotoxic Stress Response in Ewing Sarcoma. Journal of Cancer Biology and Research. 2015; 3(2):1063.

65. Paronetto MP, Miñana B, Valcárcel J. The Ewing Sarcoma Protein Regulates DNA Damage-Induced Alternative Splicing. Mol Cell. 2011; 43(3):353-68.

66. Riggi N, Knoechel B, Gillespie SM, Rheinbay E, Boulay G, Suvà ML, Rossetti NE, Boonseng WE, Oksuz O, Cook EB, Formey A, Patel A, Gymrek M, et al. EWS-FLI1 Utilizes Divergent Chromatin Remodeling Mechanisms to Directly Activateor Repress Enhancer Elements in Ewing Sarcoma. Cancer Cell. 2014; 26(5)668-81.

67. Schwentner R, Papamarkou T, Kauer MO, Stathopoulos V, Yang F, Bilke S, Meltzer PS, Girolami M, Kovar H. EWS-FLI1 employs an E2F switch to drive target gene expression. Nucleic Acids Research. 2015; 43(5):2780-9.
68. Kowalewski AA, Randall RL, Lessnick SL. Cell Cycle Deregulation in Ewing's Sarcoma Pathogenesis. Sarcoma. 2011; 2011:598704.

69. Bunting SF, Callén E, Kozak ML, Kim JM, Wong N, Lopez-Contreras AJ, Ludwig T, Baer R, Faryabi RB, Malhowski A, Chen H-T, Fernandez-Capetillo O, D’Andrea A, et al. BRCA1 Functions Independently of Homologous Recombination in DNA Interstrand Crosslink Repair. Mol Cell. 2012; 46(2):125-35. 